\title{
Cyclic Fatigue Resistance of Three Single-use NiTi Instruments after Immersion in Sodium Hypochlorite
}

\author{
${ }^{1}$ Alberto Dagna, ${ }^{2}$ Riccardo Beltrami, ${ }^{3}$ Marco Colombo, ${ }^{4}$ Marco Chiesa, ${ }^{5}$ Stefano Bianchi, ${ }^{6}$ Claudio Poggio
}

\begin{abstract}
The aim of this in vitro study was to compare the cyclic fatigue resistance of three single-use nickel-titanium (NiTi) instruments (One Shape, Reciproc and Wave One) after immersion in sodium hypochlorite $(\mathrm{NaOCl})$ solution over several time periods. A total of 135 One Shape, Reciproc R25 and Wave One Primary were tested. The 45 files of the same brand were randomly assigned to three groups $(n=15)$ and submitted to the following immersion protocol: 1 minute in $5 \% \mathrm{NaOCl}$ at $37^{\circ} \mathrm{C}, 5$ minutes in $5 \% \mathrm{NaOCl}$ at $37^{\circ} \mathrm{C}$, no immersion (as control). Cyclic fatigue test was performed rotating/reciprocating all instruments in a stainless steel curved artificial canal $\left(60^{\circ}\right.$ angle of curvature and $5 \mathrm{~mm}$ radius). The number of cycles to fracture (NCF) was determined by measuring the time to fracture. The data were compared for differences by using 2-way analysis of variance $(p<0.05)$. In general, resistance to cyclic fatigue was not significantly affected by immersion in $\mathrm{NaOCl}$. Reciproc R2 showed the highest cyclic fatigue resistance in all groups compared to One Shape and Wave One. Immersion in $\mathrm{NaOCl}$ for 1 or 5 minutes did not reduce the cyclic fatigue resistance of $\mathrm{NiTi}$ single-use instruments significantly. Reciproc were more resistant, but the new rotary single-use One Shape instruments showed mechanical resistance similar to NiTi files developed for reciprocating motion.
\end{abstract}

Keywords: Cyclic fatigue, Corrosion, NiTi, Sodium hypochlorite.

How to cite this article: Dagna A, Beltrami R, Colombo M, Chiesa M, Bianchi S, Poggio C. Cyclic Fatigue Resistance of Three Single-use NiTi Instruments after Immersion in Sodium Hypochlorite. Int J Experiment Dent Sci 2014;3(2):67-72.

\section{Source of support: Nil}

\section{Conflict of interest: None}

\section{INTRODUCTION}

Nickel-titanium (NiTi) instruments are commonly used for shaping the root canal system in endodontic practice today. ${ }^{1}$ They are more flexible and have increased cutting efficiency

\footnotetext{
${ }^{1,4-6}$ Professor, ${ }^{2,3}$ Researcher

${ }^{1,3-6}$ Department of Clinical, Surgical, Diagnostic and Pediatric Sciences, University of Pavia, Italy

${ }^{2}$ Department of Brain and Behavioral Sciences, Section of Statistics, University of Pavia, Italy
}

Corresponding Author: Claudio Poggio, Professor Department of Clinical, Surgical, Diagnostic and Pediatric Sciences University of Pavia, Italy, Phone: 0382516257, e-mail: claudio.poggio@unipv.it than conventional stainless steel files. ${ }^{2,3}$ The superelasticity of NiTi rotary files allows the clinicians to produce the desirable tapered root canal form with a reduced tendency to canal transportation. ${ }^{2-4}$ Despite these advantages, NiTi instruments appear to have a high risk of separation, ${ }^{5,6}$ mainly because of fatigue and torsional shear stresses. ${ }^{7-10}$ Many variables, such as the operational speed, the metal surface treatment and the metallurgic characterization of the NiTi alloys that could possibly influence the fatigue resistance of NiTi rotary files have been investigated. ${ }^{11}$ Canal curvature is suspected to be the predominant risk factor for instrument failure because of flexural stresses and cyclic fatigue..$^{2,12,13}$ One additional factor potentially limiting resistance to fatigue fracture is corrosion that may occur in the presence of $\mathrm{NaOCl}$ solution. ${ }^{14}$ The use of $\mathrm{NaOCl}$ to irrigate root canals is currently the gold standard to achieve tissue dissolution and disinfection. ${ }^{15}$ However, $\mathrm{NaOCl}$ does have several disadvantages, as it can bleach clothing, damage eyes in case of contact, cause periapical tissue necrosis when inadvertently injected beyond the apical foramen and create corrosion of surgical instruments. ${ }^{16,17} \mathrm{NiTi}$ instruments come into contact with $\mathrm{NaOCl}$ during disinfection ${ }^{18}$ or when the solution is present in the pulp chamber and root canal during instrumentation. ${ }^{19}$ The corrosion patterns, involving selective removal of nickel from the surface, can create micropitting that weakens the structure of the instrument. ${ }^{20,21}$

The clinician can do very little to prevent or reduce such stresses. ${ }^{10}$ In the last years, the reciprocating motion of the NiTi rotary instrument has been shown to decrease the impact of cyclic fatigue compared with rotational motion., ${ }^{9,22,23}$ Therefore, it has been recently proposed that the single-file shaping technique may simplify instrumentation protocols and avoid the risk of cross-contamination. ${ }^{10}$ Moreover, the use of only one NiTi instrument is more cost-effective, and the learning curve is considerably reduced. ${ }^{22}$

To improve fracture resistance, use of endodontic files in a reciprocating motion, along with new alloys, and new manufacturing processes have been introduced recently. ${ }^{11,24}$ $\mathrm{M}$-wire is a NiTi alloy prepared by a special thermal process that is claimed to increase flexibility and resistance to cyclic fatigue. ${ }^{25}$ Reciprocation was shown to extend the life-span of a NiTi instrument, hence resistance to fatigue, in comparison with continuous rotation. ${ }^{11,23}$ 
Recently, two M-wire NiTi endodontic file systems were introduced for use in reciprocating motion: Reciproc (VDW, Munich, Germany) and Wave One (Dentsply Maillefer, Ballaigues, Switzerland). ${ }^{26}$ To date, these instruments are sold as a single use instrument, avoiding metal weakening through prolonged clinical use; however, single use means that the same instrument can be used in 3 to 4 root canals, which could be complex and tortuous. ${ }^{27}$ The reciprocating working motion consists of a counterclockwise (cutting direction) and a clockwise motion (release of the instrument), while the angle of the counterclockwise cutting direction is greater than the angle of the reverse direction. Due to the fact that the counterclockwise angle is greater than the clockwise one, it is claimed that the instrument continuously progresses toward the terminus of the root canal. Both instruments have been evaluated in preliminary studies ${ }^{22,23,26,28-32}$ and the results regarding lifespan, cyclic fatigue resistance, shaping ability and cleaning efficiency were satisfactory.

A new concept of single-file instrumentation is that a single instrument is to be used in a full clockwise rotation. One Shape (Micro Mega, Besancon, France) belong to this group of single-file systems. The One Shape system consists of only one instrument, which has a tip size of 25 and a constant taper of 0.06 , and is characterized by different cross-sectional designs over the entire length of the working part. This instrument is made of a conventional austenite 55-NiTi alloy. In the tip region, the cross-section represents three cutting edges while in the middle of the cross-sectional design progressively changes from a three-cutting-edge design to two cutting edges. At the shank, the S-shaped cross-section shows two cutting edges, resembling the cross-sectional design of Reciproc instruments. Moreover, One Shape instruments have variable pitch length along the working part. This design is alleged to eliminate threading and binding of the instrument in continuous rotation. ${ }^{29}$ One Shape instruments are used in continuous clockwise rotation. As recommended by the manufacturers, the rotational speed for One Shape is 350 to $450 \mathrm{rpm}$ and the torque setting should be $4 \mathrm{Ncm}$.

Several authors have studied the corrosive effect of $\mathrm{NaOCl}$ on traditional endodontic NiTi instruments. ${ }^{33-35}$ Some authors have studied cyclic fatigue resistance of new reciprocating NiTi instruments after exposure to $\mathrm{NaOCl}^{36}$ The aim of this study was to assess resistance to cyclic fatigue of three single-use NiTi files (One Shape, Reciproc and Wave One) after immersion in $\mathrm{NaOCl}$ solutions for times that reflect those used in clinical practice. The null hypothesis test that there are differences in the cyclic fatigue resistance between the instruments immersed and those ones not immersed in $\mathrm{NaOCl}$ solutions.

\section{MATERIALS AND METHODS}

Three brands of single-use NiTi instruments were tested, two reciprocating files and a new rotary file. A total of 135 new NiTi instruments was used: 45 One Shape (Micro Mega, Besancon, France), 45 Reciproc R25 (VDW, Munich, Germany), 45 Wave One Primary (Dentsply Maillefer, Ballaigues, Switzerland (Table 1).

Each instrument was inspected for defects or deformities before the experiment with a stereo zoom microscope, and none were discarded. The 45 files of the same brand, all from the same production lot, were randomly assigned to three different groups of 15 each:

Group 1: Instruments were dynamically immersed in 5\% $\mathrm{NaOCl}$ (Niclor; OGNA Laboratory, Muggiò, Milan, Italy) at $37^{\circ} \mathrm{C}$ for $16 \mathrm{~mm}$ for 1 minutes.

Group 2: Instruments were dynamically immersed in 5\% $\mathrm{NaOCl}$ (Niclor; OGNA Laboratory, Muggiò, Milan, Italy) at $37^{\circ} \mathrm{C}$ for $16 \mathrm{~mm}$ for 5 minutes.

Group 3: Instruments not immersed in $5 \% \mathrm{NaOCl}$ (control).

According to Pedullà et al protocol ${ }^{36}$ for dynamic immersion, the endodontic instruments were rotated/ reciprocated respecting manufacturers' settings in small glass containers with the amount of the $\mathrm{NaOCl}$ solution necessary to contact $16 \mathrm{~mm}$ of the instruments length. One Shape was mounted on the Endo Mate DT motor (NSK, Kanuma, Japan) set to $350 \mathrm{rpm}$ and a $2 \mathrm{~N} / \mathrm{cm}$ torque with a 16:1 contra-angle in clockwise rotation. Reciproc R25 was mounted on the dedicated reciprocating motor (Silver Reciproc, VDW) used with the manufacturer configuration setup (at the preset program 'Reciproc ALL' specific to the Reciproc instruments). Wave One Primary was mounted on the dedicated reciprocating motor (Silver Reciproc, VDW) used with the manufacturer configuration setup (at the preset program 'Wave One ALL' specific to the Wave One instruments).

Immediately after removal from the solutions, all files were rinsed in bi-distilled water to neutralize the effect of $\mathrm{NaOCl}$, dried and stored in glass vials. Instruments of all

Table 1: Single-use instruments used for canal shaping

\begin{tabular}{lllll}
\hline Instrument & Manufacturer & Taper & Apical diameter & Motion \\
\hline One Shape & Micro Mega, Besancon, France & 0.06 & 25 & Continuous rotation \\
Reciproc R25 & WDV, Munich, Germany & 0.08 & 25 & Reciprocating motion \\
Wave One Primary & Dentsply Maillefer, Ballaigues, Switzerland & 0.08 & 25 & Reciprocating motion \\
\hline
\end{tabular}


Table 2: Mean NCF for each instrument type in each canal

\begin{tabular}{llll}
\hline & \multicolumn{3}{c}{ NCF $\pm S D$} \\
\cline { 2 - 4 } & Group 1 & Group 2 & Group 3 \\
\hline One Shape & $652.43 \pm 61.71^{\mathrm{a}}$ & $603.07 \pm 46.68^{\mathrm{b}}$ & $77 \pm 38.31^{\mathrm{c}}$ \\
Reciproc R25 & $802.63 \pm 58.36$ & $771.78 \pm 42.54$ & $749.39 \pm 46.49$ \\
Wave One Primary & $617.64 \pm 52.02^{\mathrm{a}}$ & $622.63 \pm 48.48^{\mathrm{b}}$ & $590.31 \pm 55.91^{\mathrm{c}}$ \\
\hline
\end{tabular}

Different superscript letters indicate no significant differences $(p>0.05)$ between groups with the same letter. Groups with no superscript letter indicate significant differences between groups in vertical row $(p<0.05)$

three groups of each brand were then subjected to cyclic fatigue testing using a mechanical device specifically developed for the purpose that allowed a reproducible simulation of an instrument confined in a curved canal. ${ }^{32}$ The apparatus was connected to the same motors set with the same programs used for the dynamic immersion. In this way, the endodontic instruments were able to rotate/reciprocate freely within a tempered stainless steel artificial canal at a constant pressure. The artificial canal was manufactured by reproducing an instrument's size and taper. It provided the instrument with a suitable simulated root canal with a $60^{\circ}$ angle of curvature and $5 \mathrm{~mm}$ radius of curvature measured according to the method of Schneider. ${ }^{37}$ The centre of the curvature was $6 \mathrm{~mm}$ from the tip of the instrument, and the curved segment of the canal was approximately $6 \mathrm{~mm}$ in length. The diameter of the simulated canals is higher than the instruments, allowing free rotation. To reduce friction as the instruments contacted the metal canal walls, lubricant oil filled the canal space after each use. Each instrument was allowed to rotate/reciprocate with spontaneous pecking movement until fracture. The time to fracture was recorded visually with a $1 / 100$-s chronometer and timing was stopped as fracture is detected visually and/or audibly. The number of cycles to fracture (NCF) was calculated by multiplying the time (seconds) to fracture by the number of rotations or cycles per second, regardless of the rotation direction. Note: the manufacturers claim that the reciproc mode has $300 \mathrm{rpm}$ and Wave One mode has $350 \mathrm{rpm} .{ }^{27}$
Data were analyzed by using 2-way analysis of variance in software (SPSS 15.0, Chicago, IL). Post-hoc Bonferroni test was applied to identify the groups that were significantly different from others. Statistical significance was set at p-value less than $5 \%$.

\section{RESULTS}

The NCF's means for each file in each group are presented in Table 2. The Figure 1 presents the means and the standard deviations for each instrument type in each of the three groups. A higher NCF is caused by a higher resistance to cyclic fatigue of the tested instruments.

The 2-way analysis of variance showed the absence of a statistically significant difference among the NCF's means of the instruments when used in association with sodium hypochlorite solutions $(\mathrm{p}>0.05)$. $\mathrm{R} 25$ had the best fatigue resistance in groups 1,2 and $3(p<0.05)$. Wave one and OS had similar cyclic fatigue resistance values in all the groups $(p>0.05)$.

\section{DISCUSSION}

The three instruments used in the present study were selected, because they are to date the only commercially available instruments designed for single-use. The new endodontic single-use files for reciprocating motion have been introduced with good results, ${ }^{24,29,31,33,38,39}$ but the latest single-use instruments have been developed for continuous rotation. Reciproc and Wave One are used in reciprocating

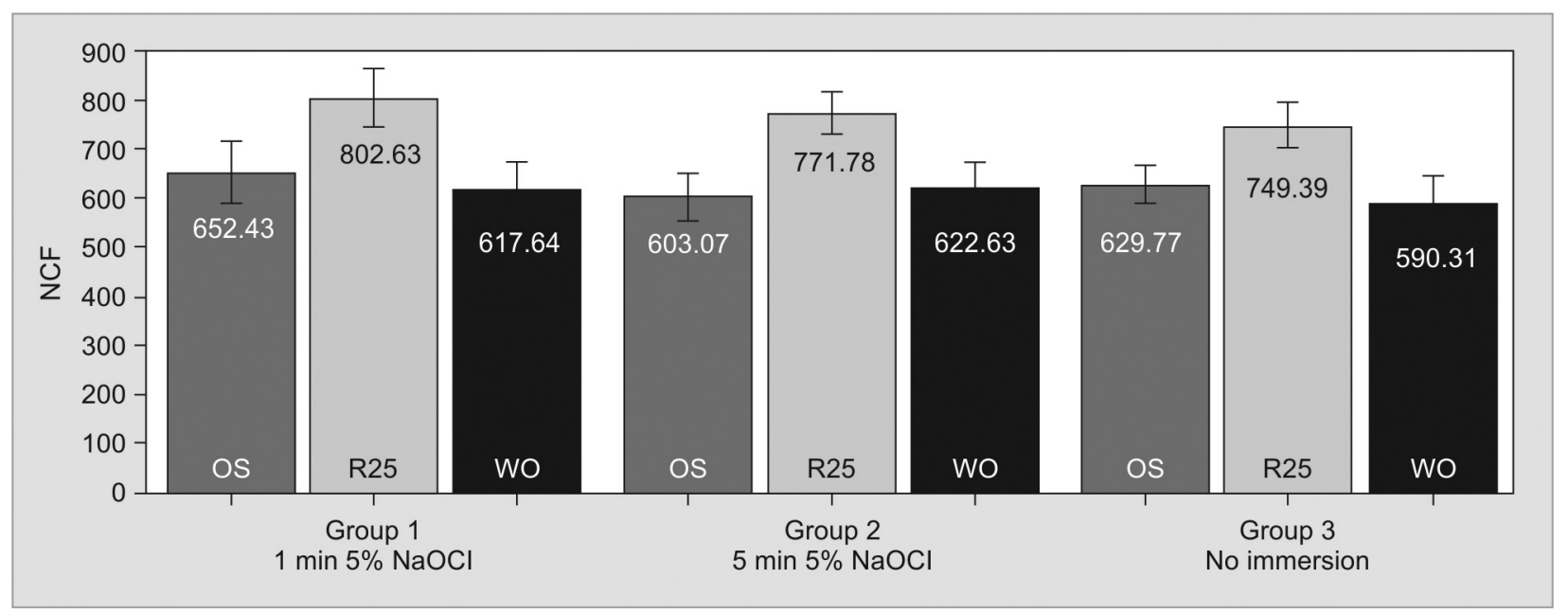

Fig. 1: Mean NCF \pm SD for each instrument type in each canal 
motion, One Shape is used in continuous rotation. Reciprocation and continuous rotation are different movements that could agitate $\mathrm{NaOCl}$ solution differently. ${ }^{40}$

Nickel-titanium rotary files have become a standard tool to shape root canals, but they tend to unexpectedly break because of cyclic fatigue, which is induced by the alternating tension-compression cycles to which they are subjected when flexed in the maximum curvature region of the canal and rotated. ${ }^{6}$ For this reason, important changes have been combined to make NiTi instruments safer: improved alloys, different movements (reciprocating motion), and new concepts of use (single-use). A new approach using only one ProTaper F2 instrument in a reciprocating movement was introduced in 2008 by Yared, ${ }^{41}$ thereby presenting a new perspective for NiTi files. The employment of reciprocating motion instead of the conventional continuous rotation method was suggested as an advantage for the preparation of curved canals with the use of one single NiTi file. ${ }^{22-24,28}$ The use of a single NiTi instrument is likely to be more cost-effective than the conventional multifile NiTi rotary systems and the learning curve is considerably reduced as a result of technique simplification and reduction of the endodontic instruments. ${ }^{27}$ The new single-use systems have been introduced to shape root canals with only one file: this technique simplification allows saving time and cost for endodontic treatment. ${ }^{31}$ However, to shape root canals with only one file, the instrument will be subject to a great deal of stresses, both torsional and cyclic (bending) fatigue. This instrument is not used for further canals and not requires thermal sterilization in autoclave, so it will be not exposed to other stresses.

The aim of this study was to evaluate and compare the cyclic fatigue resistance of three new different single-use NiTi endodontic instruments in four artificial canals after immersion in $\mathrm{NaOCl}$ solutions for different times.

According to Pedullà et $\mathrm{al}^{36}$ all instruments were dynamically immersed in $5 \% \mathrm{NaOCl}$ solution for 1 or 5 minutes and then subjected to cyclic fatigue testing using a simulated root canal with $60^{\circ}$ angle of curvature and $5 \mathrm{~mm}$ radius of curvature. The same reciprocating motions 'Reciproc ALL' or 'Wave One ALL' were used for the cyclic fatigue tests and the previous dynamic immersion in $5 \% \mathrm{NaOCl}$ solution for 1 or 5 minutes of Reciproc R25 and Wave One Primary, respectively. These two types of preset reciprocating motions have different angles of rotation and velocities. Manufacturers claim a rotation of $150^{\circ}$ counterclockwise (CCW) and $30^{\circ}$ clockwise $(\mathrm{CW})$ with an approximate velocity of $300 \mathrm{rpm}$ for 'Reciproc ALL' mode, while a rotation of $170^{\circ}$ $\mathrm{CCW}$ and $50^{\circ} \mathrm{CW}$ with an approximate velocity of $350 \mathrm{rpm}$ is claimed for 'Wave One ALL' mode 26. One Shape was mounted on a conventional engine with speed set at 350 rpm for previous dynamic immersion and then for testing into the artificial canal.

Reciproc and Wave One reciprocating file systems are made of the same innovative M-wire NiTi alloy but have different cross-sections, S-shape and concave triangular shape for Reciproc and Wave One respectively. ${ }^{26}$ It was reported that the larger cross-sectional area would have a higher flexural and torsional stiffness, and thus the file design (cross-sectional shape, diameters of core, etc.) would have a significant influence on the torsional and bending (hence, fatigue) resistance. ${ }^{26}$ Instruments made from M-wire or R-phase NiTi was reported to offer greater flexibility and resistance to cyclic fatigue than the files from traditional alloys. ${ }^{23,27} \mathrm{Kim}$ et $\mathrm{al}^{26}$ assessed the cyclic fatigue resistance and torsional resistance of two reciprocating motion systems, Reciproc R25 and Wave One Primary file, compared with ProTaper F2 in a continuous rotation. The results showed that both reciprocating files demonstrated higher cyclic fatigue and torsional resistance than ProTaper. This would explain why Wave One Primary exhibited higher fatigue resistance despite its cross-sectional shape and area both being similar to ProTaper. They observed higher cyclic fatigue but lower torsional resistance in Reciproc than Wave One. It implies that Reciproc R25 possesses lower flexural stiffness and smaller polar moment of inertia than Wave One. In other words, Wave One had a higher torsional stiffness than Reciproc. In this study, Reciproc R25 exhibited significantly higher cyclic fatigue resistance than other instruments in all canals, probably because of the NiTi alloy, the instrument geometry and the reciprocating movement: all single-use instruments NiTi files were more resistant than traditional rotary instrument used as control.

One Shape is made by the conventional austenite 55NiTi alloy, but the design is really innovative. One Shape is characterized by different cross-sectional designs over the entire length of the working part: in the tip region, the cross-section represents three cutting edges while in the middle of the cross-sectional design progressively changes from a three-cutting-edge design to two cutting edges. At the shank, the S-shaped cross-section shows two cutting edges, resembling the cross-sectional design of Reciproc instruments. Moreover, One Shape instruments have variable pitch length along the working part. This design is alleged to eliminate threading and binding of the instrument in continuous rotation, in order to guarantee more flexibility. ${ }^{29}$ In this study, One Shape instruments showed cyclic fatigue resistance similar to Wave One. Actually only two studies included the One Shape instruments. Burklein et al ${ }^{38}$ compared the shaping ability of three different single-file systems (Reciproc R25, One Shape and F360, another single-use file having a size 25 at the tip and a taper of 0.04 made for 
continuous rotation by Komet Brasseler, Lemgo, Germany) with Mtwo rotary instruments (respecting the five files instrumentation sequence) during the preparation of curved root canals in extracted teeth. Under the conditions of this study, all instruments respected the original canal curvature well and were safe to use. They concluded that the use of Reciproc and One Shape instruments required less time to prepare the curved canals compared with Mtwo and F360. Dagna et $\mathrm{al}^{42}$ investigated the capability of different NiTi instruments in disinfecting root canals previously infected with Enterococcus faecalis. Extracted teeth were inoculated with cells of E. faecalis strain and shaped with different NiTi instruments (MTwo and Revo-S conventional instruments vs Reciproc and One Shape) under irrigation with $\mathrm{NaOCl}$ and $17 \%$ EDTA solutions. The number of colony forming units $(\mathrm{CFU}) / \mathrm{ml}$ of $E$. faecalis was evaluated for each group and the results showed that all the NiTi instrumentations efficiently reduced $E$. faecalis counts and no significant differences were found among them.

In this experimental conditions, reciprocating dynamic immersion in $\mathrm{NaOCl}$ for 1 or 5 minutes did not reduce significantly the cyclic fatigue resistance of reciprocating NiTi files. Significant differences were found between the different NiTi files. Reciproc R25 was more resistant to cyclic fatigue than Wave One Primary and One Shape. The results are in agreement with recent reports that showed a higher cyclic fatigue resistance for Reciproc than Wave One. ${ }^{27,31}$ As these instruments have the same tip size (diameter at D0), apical taper and the same alloy, these differences are probably due to their different cross-sectional design.

No differences were found between Wave One Primary and One Shape. But no publications are available to date about cyclic fatigue of One Shape. A reciprocating motion may decrease the impact of cyclic fatigue on NiTi rotary instrument life compared with rotational motion. ${ }^{43}$ But Oh et al ${ }^{44}$ verified that the instrument design, particularly the crosssectional area (CSA), could also affect the fatigue behavior when subjected to torsion or bending. Sections with a larger CSA are more susceptible to fatigue fracture than smaller sections when rotating at the same curvature. Moreover, an electropolishing procedure has been attempted during the manufacturing process to reduce the number of machining defects and residual stress of ground NiTi rotary instruments: the grinding of file blanks during the manufacture of NiTi rotary instruments causes many machining defects. This procedure removes the outer layer of a metal, leaving the surface free of contaminants, microcracks, and workinduced residual stress. This means that the resistance to fatigue failure can be enhanced by a smooth defect-free surface. ${ }^{44}$ Variable cross-section with small residual core and electropolished surfaces of One Shape could explain these good results.
Reciproc R25, thanks to their geometry, alloy and reciprocating motion exhibited the better results. One Shape rotary instruments seem to have mechanical resistance similar to Wave One NiTi files, even if not developed for reciprocating motion: this could be justified by the manufacturing process and the innovative geometry of this file with variable cross-section.

\section{CONCLUSION}

Immersion in $\mathrm{NaOCl}$ for 1 or 5 minutes did not reduce significantly the cyclic fatigue resistance of single-use NiTi instruments. The NCF of Reciproc R25 was greater than One Shape and Wave One Primary. One Shape Rotary file showed mechanical resistance similar to NiTi files developed for reciprocating motion.

\section{REFERENCES}

1. Torabinejad M, Walton RE. Endodontics: principles and practice. 4th ed. St. Louis, Missouri: Saunders Elsevier; 2009.

2. Peters OA. Current challenges and concepts in the preparation of root canal systems: a review. J Endod 2004;30(8):559-567.

3. Schafer E, Schulz-Bongert U, Tulus G. Comparison of hand stainless steel and nickel titanium rotary instrumentation: a clinical study. J Endod 2004;30(6):432-435.

4. Chen JL, Messer HH. A comparison of stainless steel hand and rotary nickel-titanium instrumentation using a silicone impression technique. Aust Dent J 2002;47(1):12-20.

5. Sattapan B, Nervo GJ, Palamara JE, Messer HH. Defects in rotary nickel-titanium files after clinical use. J Endod 2000;26(3):161-165.

6. Arens FC, Hoen MM, Steiman HR, Dietz GC Jr. Evaluation of single-use rotary nickel-titanium instruments. J Endod 2003;29(10):664-666.

7. Peters OA, Barbakow F. Dynamic torque and apical forces of ProFile 0.04 rotary instruments during preparation of curved canals. Int Endod J 2002;35(4):379-389.

8. Lopes HP, Moreira EJ, Elias CN, de Almeida RA, Neves MS. Cyclic fatigue of ProTaper instruments. J Endod 2007;33(1):55-57.

9. Varela-Patino P, Ibanez-Parraga A, Rivas-Mundina B, Cantatore G, Otero XL, Martin-Biedma B. Alternating vs continuous rotation: a comparative study of the effect on instrument life. J Endod 2010;36(1):157-159.

10. Berutti E, Paolino DS, Chiandussi G, Alovisi M, Cantatore G, Castellucci A, Pasqualini D. Root canal anatomy preservation of Wave One reciprocating files with or without glyde path. J Endod 2012;38(1):101-104.

11. Gambarini G, Grande NM, Plotino G, Somma F, Garala M, De Luca M, Testarelli L. Fatigue resistance of engine-driven rotary nickel-titanium instruments produced by new manufacturing methods. J Endod 2008;34(8):1003-1005.

12. Peters OA, Peters CI, Schonenberger K, Barbakow F. ProTaper rotary root canal preparation: assessment of torque and force in relation to canal anatomy. Int Endod J 2003;36(2):93-99.

13. Hulsmann M, Peters OA, Dummer PMH. Mechanical preparation of root canals: shaping goals, techniques and means. Endodontic Topics 2005;10(3):30-76.

14. Sonntag D, Heithecker K. Korrosion von Nickel-Titan-Instrumenten. Endodontie 2006;15(1):23-30. 
15. Zehnder M. Root canal irrigants. J Endod 2006;32(5):389-398.

16. White RR, Hays GL, Janer LR. Residual antimicrobial activity after canal irrigation with chlorhexidine. J Endod 1997;23(4):229-231.

17. Hulsmann M, Hahn W. Complications during root canal irrigation-literature review and case reports. Int Endod J 2000; 33(3):186-193.

18. Savage NW, Walsh IJ. The use of autoclaves in the dental surgery. Aust Dent J 1995;40(3):197-200.

19. Bystrom A, Sundqvist G. Bacteriologic evaluation of the effect of $0.5 \% \mathrm{NaOCl}$ in endodontic therapy. Oral Surg Oral Med Oral Pathol Oral Radiol Endod 1983;55(3):307-312.

20. Sarkar NK, Redmond W, Schwaninger B, Goldberg AJ. The chloride corrosion behaviour of four orthodontic wires. J Oral Rehabil 1983;10(2):121-128.

21. Oshida Y, Sachdeva RC, Miyazaki S. Microanalytical characterization and surface modification of TiNi orthodontic archwires. Biomed Mater Eng 1992;2(2):51-69.

22. De-Deus G, Moreira EJ, Lopes HP, Elias CN. Extended cyclic fatigue life of F2 ProTaper instruments used in reciprocating movement. Int Endod J 2010;43(12):1063-1068.

23. You SY, Bae KS, Baek SH, Kum KY, Shon WJ, Lee W. Lifespan of one nickel-titanium rotary file with reciprocating motion in curved root canals. J Endod 2010;36:1991-1994.

24. Franco V, Fabiani C, Taschieri S, Malentacca A, Bortolin M, Del Fabbro M. Investigation on the shaping ability of nickeltitanium files when used with a reciprocating motion. J Endod. 2011;37(10):1398-1401.

25. Al-Hadlaq SM, Aljarbou FA, Al-Thumairy RI. Evaluation of cyclic flexural fatigue of M-wire nickel-titanium rotary instruments. J Endod 2010;36(2):305-307.

26. Kim HC, Kwak SW, Cheung GS, Ko DH, Chung SM, Lee W. Cyclic fatigue and torsional resistance of two new nickeltitanium instruments used in reciprocation motion: Reciproc versus Wave One. J Endod 2012;38(4):541-544.

27. Plotino G, Grande NM, Testarelli L, Gambarini G. Cyclic fatigue of Reciproc and Wave One reciprocating instruments. Int Endod J 2012;45(7):614-618.

28. Berutti E, Chiandussi G, Paolino DS, Scotti N, Cantatore G, Castellucci A, Pasqualini D. Canal shaping with Wave One reciprocating files and Pro Taper system: a comparative study. J Endod 2012;38(4):505-509.

29. Burklein S, Hiller C, Huda M, Scha€fer E. Shaping ability and cleaning effectiveness of Mtwo vs coated and uncoated Easy Shape instruments in severely curved root canals of extracted teeth. Int Endod J 2011;44(5):447-457.

30. Dietrich MA, Kirkpatrick TC, Yaccino JM. In vitro canal and isthmus debris removal of the Self Adjusting File, K3, and Wave One files in the mesial root of human mandibular molars. J Endod 2012;38(8):1140-1144.

31. Kim HC, Hwang YJ, Jung DW, You SY, Kim HC, Lee W. Micro-computed tomography and scanning electron microscopy comparisons of two nickel-titanium rotary root canal instruments used with reciprocating motion. Scanning 2013;35(1):112-118.

32. Plotino G, Grande NM, Cordaro M, Testarelli L, Gambarini G. A review of cyclic fatigue testing of nickel-titanium rotary instruments. J Endod 2009;35:1469-1476.

33. Haikel Y, Serfaty R, Wilson P, Speisser JM, Allemann C. Mechanical properties of nickel-titanium endodontic instruments and the effect of sodium hypochlorite treatment. J Endod 1998;24(11):731-735.

34. Peters OA, Roehlike JO, Baumann MA. Effect of immersion in sodium hypochlorite on torque and fatigue resistance of nickeltitanium instruments. J Endod 2007;33(5):589-593.

35. Pedullà E, Grande NM, Plotino G, Pappalardo A, Rapisarda E. Cyclic fatigue resistance of three different instruments after immersion in sodium hypochlorite. J Endod 2012;37(8):11391142.

36. Pedullà E, Grande NM, Plotino G, Palermo F, Gambarini G, Rapisarda E. Cyclic fatigue resistance of two reciprocating nickeltitanium instruments after immersion in sodium hypochlorite. Int Endod J 2013;46(2):155-159.

37. Schneider SW. A comparison of canal preparations in straight and curved root canals. Oral Surg Oral Med Oral Pathol Oral Radiol Endod 1971;32(2):271-275.

38. Burklein S, Benten S, Schafer E. Shaping ability of different single-file systems in severely curved root canals of extracted teeth. Int Endod J 2013;46(6):590-597.

39. Burklein S, Hinschitza K, Dammaschke T, Schafer E. Shaping ability and cleaning effectiveness of two single-file systems in severely curved root canals of extracted teeth: Recproc and Wave One vs Mtwo and ProTaper. Int Endod J 2012;45(5):449-461.

40. Siqueira JF jr, Machado AG, Silveira RM, Lopes HP, de Uzeda M. Evaluation of the effectiveness of sodium hypochlorite used with three irrigation methods in the elimination of Enterococcus faecalis from the root canal, in vitro. Int Endod J 1997;30(4): 279-282.

41. Yared G. Canal preparation using only one NiTi rotary instrument: preliminary observations. Int Endod J 2008;41(4):339-344.

42. Dagna A, Arciola CR, Visai L, Selan L, Colombo M, Bianchi S, Poggio C. Antibacterial efficacy of conventional and singleuse NiTi endodontic instruments: an in vitro microbiological evaluation. Int J Artificial Organs 2012;35(10):826-831.

43. Castello-Escrivà R, Alegre-Domingo T, Faus-Matoses V, Roman-Richon S, Faus-Llacer VJ. In vitro comparison of cyclic fatigue resistance of ProTaper, Wave One and Twisted Files. J Endod 2012;38(11):1521-1524.

44. Oh SR, Chang SW, Lee Y, Gu Y, Son WJ, Lee W, Baek SH, Bae KS, Choi GW, Lim SM, Kum KY. A comparison of nickel-titanium rotary instruments manufactured using different methods and cross-sectional areas: ability to resist cyclic fatigue. Oral Surg Oral Med Oral Pathol Oral Radiol Endod 2012;109(4): 622-628. 